\title{
In situ ultraviolet treatment in an Ar ambient upon p-type hydrogenated amorphous silicon-carbide windows of hydrogenated amorphous silicon based solar cells
}

\author{
Seung Yeop Myong, ${ }^{\text {a) }}$ Sang Soo Kim, and Koeng Su Lim \\ Department of Electrical Engineering and Computer Science, KAIST, 373-1 Guseong-dong, Yuseong-gu, \\ Daejeon 305-701, Republic of Korea
}

(Received 31 October 2003; accepted 4 May 2004; published online 17 June 2004)

\begin{abstract}
We proposed an in situ postdeposition ultraviolet treatment in an Ar ambient (UTA) to improve the $p / i$ interface of amorphous silicon based solar cell. We have increased the conversion efficiency by $\sim 16 \%$ by improving the built-in potential and reducing recombination at the $p / i$ interface. Through spectroscopic ellipsometry and Fourier-transform infrared measurements, it is concluded that the UTA process induces structural modification of the $p$-type hydrogenated amorphous silicon-carbide $(p-a-\mathrm{SiC}: \mathrm{H})$ window layer. An ultrathin $p-a-\mathrm{SiC}: \mathrm{H}$ contamination layer formed during the UTA process acts as a buffer layer at the interface. (C) 2004 American Institute of Physics. [DOI: 10.1063/1.1767601]
\end{abstract}

Hydrogenated $p$-type amorphous silicon-carbide ( $p$ - $a$ $-\mathrm{SiC}: \mathrm{H})$ films have been widely used as window materials for amorphous silicon $(a-\mathrm{Si}: \mathrm{H})$ based solar cells due to their wide optical band gap. However, an abrupt heterojunction between a $p-a-\mathrm{SiC}: \mathrm{H}$ window layer and an intrinsic hydrogenated amorphous silicon $(i-a-\mathrm{Si}: \mathrm{H})$ absorber layer generates a considerable recombination loss of photogenerated carriers due to a highly defective interface with a short carrier lifetime. In addition, the low electrical conductivity of $p$ - $a$-SiC:H severely limits the overall cell performance.

Various buffer layers have been developed to solve the $p$ - $a$-SiC: $\mathrm{H} / i-a-\mathrm{Si}: \mathrm{H}$ interface problem. ${ }^{1-3}$ The insertion of these buffer layers at the $p / i$ interface remarkably improves the conversion efficiency by forming a strong electric field in the absorber layer and diminishing electron backdiffusion to $p$-a-SiC:H. However, the additional buffer design is quite complex due to its various deposition parameters. Alternatively, the cell efficiency has been considerably improved by modifying the $p / i$ interface through $\mathrm{H}_{2}$ treatments. ${ }^{4,5}$ However, since hydrogen plasma and photo-assisted hydrogen radicals significantly etch the surface of $p-a-\mathrm{SiC}: \mathrm{H}$, the window layer thickness and treatment time must be carefully controlled.

In this letter, an in situ postdeposition ultraviolet-UV treatment in an Ar ambient (UTA) in a photoassisted chemical vapor deposition (photo-CVD) system has been proposed in order to easily overcome the recombination loss at the $p / i$ interface without affecting the $p-a-\mathrm{SiC}: \mathrm{H}$ layer thickness. Argon has been known to be a useful dilution gas for enhancing the crystallinity of $p$-type hydrogenated microcrystalline silicon $(p-\mu c-\mathrm{Si}: \mathrm{H})^{6}$ or the stability of $i-a-\mathrm{Si}: \mathrm{H}^{7}$ In addition, Branz et al. reported improved stability of $a-\mathrm{Si}: \mathrm{H}$ photosensitivity by UV illumination due to mobile hydrogen atom $(\mathrm{H})$ migration in the bulk. ${ }^{8}$

Using a photo-CVD system, we fabricated pin-type solar cells at $250{ }^{\circ} \mathrm{C}$ with a reference structure (reference cell) of glass $/ \mathrm{SnO}_{2}: \mathrm{F} / p-a-\mathrm{SiC}: \mathrm{H}(17.5 \mathrm{~nm}) / i-a-\mathrm{Si}: \mathrm{H}$ $(600 \mathrm{~nm} / \mathrm{n}-\mu \mathrm{c}-\mathrm{Si}: \mathrm{H})(40 \mathrm{~nm}) / \mathrm{Al}$, and an area of $0.092 \mathrm{~cm}^{2}$.

\footnotetext{
${ }^{a)}$ Electronic mail: myongsy@kaist.ac.kr
}

$p$ - $a$-SiC: $\mathrm{H}$ films were grown by direct decomposition of a mixture of $\mathrm{Si}_{2} \mathrm{H}_{6}, \mathrm{~B}_{2} \mathrm{H}_{6}$ and $\mathrm{C}_{2} \mathrm{H}_{4}$ reactant gases. To dissociate the mixture, a low-pressure mercury $(\mathrm{Hg})$ lamp with resonance lines of 184.9 and $25.7 \mathrm{~nm}$ was used as an UV light source. Prior to the UV treatment, we first turned off the UV lamp and then rapidly evacuated the reaction chamber to a pressure of $10^{-6}$ Torr in order to reduce the chemical adsorption of species arriving from the chamber wall and remaining reactant gases. Maintaining a heating block lying beneath a substrate holder at the temperature of $250{ }^{\circ} \mathrm{C}$, we executed in situ UV treatments upon $p$ - $a$-SiC: $\mathrm{H}$ window layers for $30 \mathrm{~min}$ under an ultrahigh vacuum of $10^{-6}$ Torr ( UT cell) or Ar ambient (UTA cell). During UV treatments, we closed all valves of the chamber after introducing Ar gas and inspected a near-surface temperature via a thermal couple contacted on a substrate holder.

Figure 1 shows the current-voltage $(\mathrm{J}-\mathrm{V})$ characteristics of solar cells measured under $100 \mathrm{~mW} / \mathrm{cm}^{2}$ (AM 1.5) solar simulator irradiation. Compared to the reference cell, the UT cell does not display noticeable improvement, except for a slightly enhanced fill factor (FF) value. The UTA cell, on the other hand, exhibits considerably enhanced conversion efficiency due to increased open-circuit voltage $\left(V_{\text {oc }}\right)$ and $\mathrm{FF}$ values. We fabricated UTA cells at different $\mathrm{Ar}$ pressure

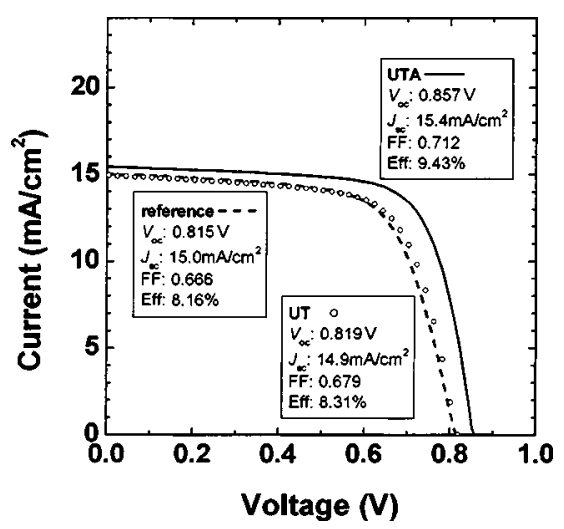

FIG. 1. Photo $J-V$ characteristics of $a-\mathrm{Si}: \mathrm{H}$ solar cells with and without the postdeposition (UV) treatment for the $p-a-\mathrm{SiC}: \mathrm{H}$ window layer. 


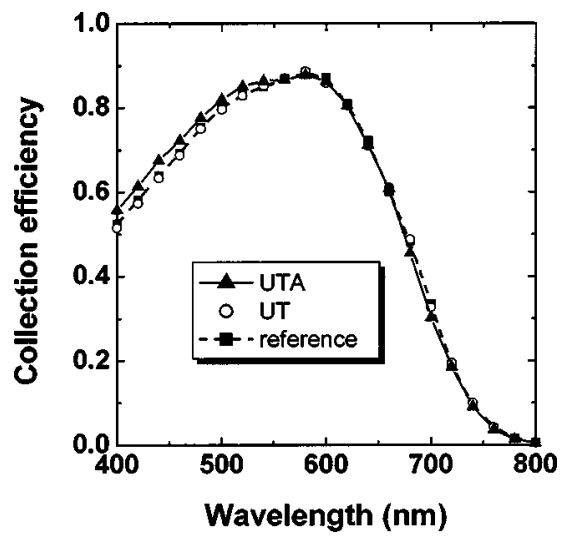

FIG. 2. Spectral response of solar cells with and without the postdeposition $\mathrm{UV}$ treatment for the $p-a-\mathrm{SiC}: \mathrm{H}$ window layer.

(1-3 Torr). However, there was no noticeable difference in the cell performance. It is clear that Ar plays an important role during UV treatments for $p-a-\mathrm{SiC}: \mathrm{H}$ window layers. The corresponding spectral collection efficiency is shown in Fig. 2. The UT cell exhibits a nearly identical spectral response with the reference cell. However, the UTA process enhances the collection efficiency in this range to a small extent, and thus increases the short-circuit current $\left(J_{\mathrm{sc}}\right)$ from 15.0 to $15.4 \mathrm{~mA} / \mathrm{cm}^{2}$.

We have investigated the structural modification of the $p$ - $a$-SiC: H layer via ex situ phase-modulation spectroscopic ellipsometry (SE) measurements. 30 min UT and UTA processes were executed for $p-a-\mathrm{SiC}: \mathrm{H}$ single layers prepared under the same conditions as the solar cell fabrication. We fitted the experimental SE angles $(\Psi, \Delta)$ by using the TaucLorentz empirical model. ${ }^{3,9}$ Figure 3 shows the fitted real and imaginary part of the dielectric functions $\left(\varepsilon_{1}, \varepsilon_{2}\right)$ of $p-a$ -SiC: $\mathrm{H}$ before and after UV treatments. Typical fitted parameters $d$ (in nm), $A, C$, and $E_{g}$ (in $\mathrm{eV}$ ) represent, respectively, the film thickness, amplitude of the $\varepsilon_{2}$ spectrum, oscillator broadening factor, and Tauc optical band gap are provided in Fig. 3. Both $\varepsilon_{1}$ and $\varepsilon_{2}$ spectra very slightly decrease in the peak amplitude without changing their peak positions after the UT, compared to the dielectric functions of as-grown $p$ - $a$-SiC:H. The $d$ and $C$ parameters slightly increase, while $A$ and $E_{g}$ slightly decrease. The small increase in $d$ and decrease in $A$ imply that film density, or more specifically $\mathrm{Si}-\mathrm{Si}$ bond packing density decreases due to the

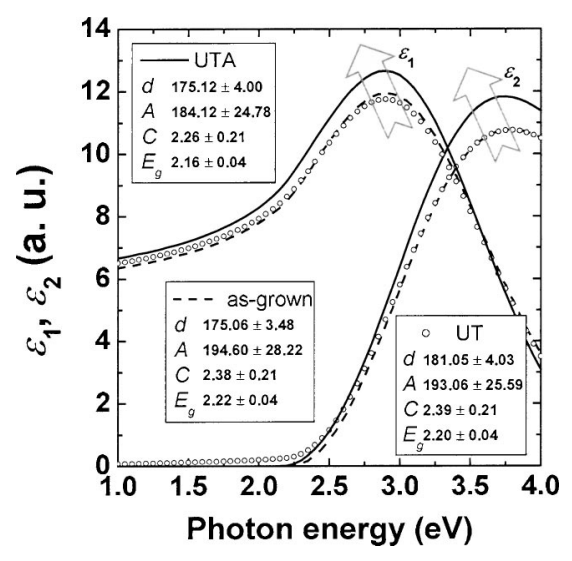

FIG. 3. Fitted real-part $\left(\varepsilon_{1}\right)$ and imaginary-part $\left(\varepsilon_{2}\right)$ of dielectric functions of $p-a-\mathrm{SiC}: \mathrm{H}$ films with and without UV treatment. Four fitted parameters $d$ (in $\mathrm{nm}$ ), $A, C$, and $E_{g}$ (in $\mathrm{eV}$ ) are included.

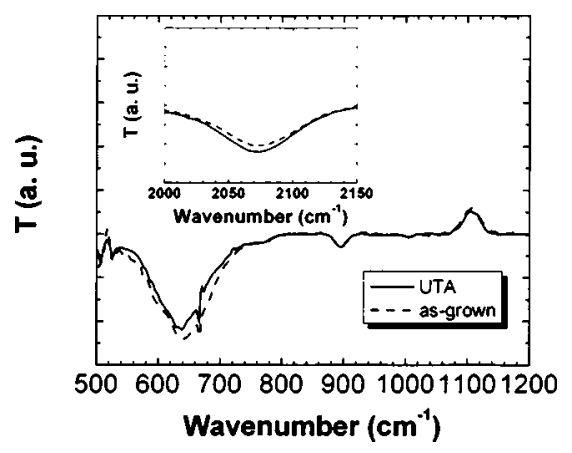

FIG. 4. Comparison of FTIR spectra between as-grown 200-nm-thick $p-a-\mathrm{SiC}: \mathrm{H}$ and the same film after the UTA.

UT. Also, the increase in the parameter $C$ indicates a reduced order in the film. ${ }^{10}$ Accordingly, we can be speculate that an ultrathin contaminant layer is formed at the surface after UV irradiation due to the adsorption of residual species. On the contrary, $\varepsilon_{1}$ and $\varepsilon_{2}$ spectra all shift to lower energy and increase in peak amplitude after the UTA. $A, C$, and $E_{g}$ values all decrease, while $d$ shows no detectable change. The decrease in $A$ and $C$ indicate, respectively, the decrease in film density and improved film order after the UTA. In our pervious work, $d$ of thicker $p-a-\mathrm{SiC}: \mathrm{H}$ decreases from 286 to $275 \mathrm{~nm}$ through an UTA performed in a clean load lock chamber. ${ }^{11}$ It can be attributed to the structural modification of the $p-a-\mathrm{SiC}: \mathrm{H}$ bulk after the UTA process: excited Ar due to UV illumination breaks weak $\mathrm{Si}-\mathrm{H}$ bonds by releasing hydrogen atoms. Hydrogen atoms then migrate through the lattice, and are subsequently emitted from the surface. The loss of bonded $\mathrm{H}$ is followed by $\mathrm{Si}-\mathrm{Si}$ bond reconstruction. Consequently, film density increases with diminishing its bulk thickness. Although the Ar ambient hold in the chamber improves the thermal contact between the heating block and the sample holder before the UTA process, the near-surface temperature rapidly saturates at $248{ }^{\circ} \mathrm{C}$ after UV illumination. Thus, the effect of the increase in the near-surace temperature on the structural modification can be ignored. In the case of the in situ UTA for the ultrathin $p$ - $a$-SiC:H performed in the $p$ chamber, the film thickness is almost unchanged because the decrease in bulk layer due to the structural modification compensates the increase in the thickness due to the contaminant surface formation.

Figure 4 displays the Fourier-transform infrared (FTIR) spectra of 200-nm-thick $p$ - $a$-SiC:H prepared on $c$-Si. The absorption peak at $\sim 640 \mathrm{~cm}^{-1}$ is attributed to the $\mathrm{Si}-\mathrm{H}$ wagging/rocking vibrational mode. The peak at $\sim 2070 \mathrm{~cm}^{-1}$ is attributed to the $\left(\mathrm{Si}: \mathrm{H}_{2}\right)_{n}$ stretching mode, which can be promoted by the incorporation of carbon atoms ${ }^{12}$ or the generation of mocrovoids. ${ }^{13}$ after the UTA, the absorption band at $\sim 640 \mathrm{~cm}^{-1}$ decreases in strength, which reflects the decrease in hydrogen content. The small increases in the absorption band at $\sim 2070 \mathrm{~cm}^{-1}$ can be ascribed to the in crease in microvoids fraction due to the $\mathrm{H}$ evolution and the carbon contamination at the surface. However, invariant peaks near 890 and $1100 \mathrm{~cm}^{-1}$ imply that the in situ UTA process is free from the oxygen contamination. Therefore, we can conclude that an ultrathin $p$ - $a$-SiC: $\mathrm{H}$ layer with smaller density than the $p-a-\mathrm{SiC}: \mathrm{H}$ window is formed after the UTA. From the reduced $E_{g}$ of the $p$ layer after the UV treatments (see Fig. 3 ), we consider that the contamination layer has a narrower optical band gap than the window because of lower carbon 


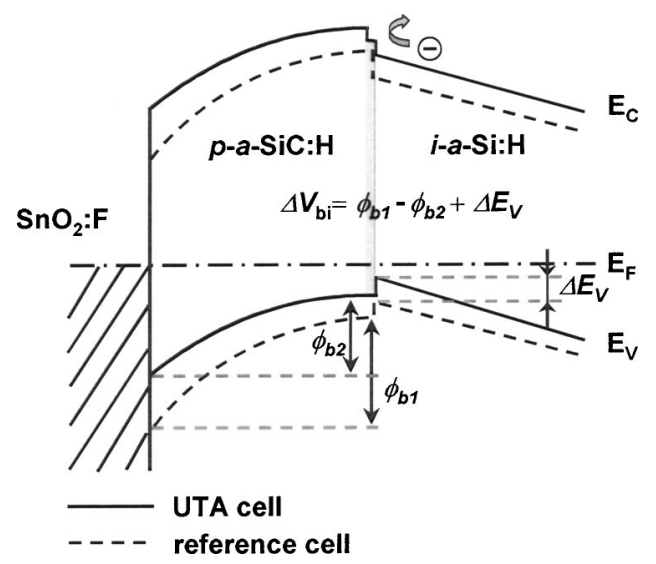

FIG. 5. Band diagram that explains the increase in the built-in potential $\left(\Delta V_{\text {bi }}\right)$ by the in situ UTA for the $p-a-\mathrm{SiC}: \mathrm{H}$ window layer in the $a-\mathrm{Si}: \mathrm{H}$ solar cell. The $\Phi_{b 2}-\Phi_{b 2}$ value denotes a potential difference at the $\mathrm{SnO}_{2}: \mathrm{F} / p-a-\mathrm{SiC}: \mathrm{H}$ interface originating from the UTA. The $\Delta E_{v}$ value describes the band lift arising from the Fermi level location of the window layer closer to the valence band edge of the $i-a-\mathrm{Si}: \mathrm{H}$ absorber. The graycolored ultrathin contaminant $p-a-\mathrm{SiC}: \mathrm{H}$ layer acts as a buffer layer reducing the recombination loss at the $p / i$ interface.

content. This impacts the initial solar cell performance by grading the abrupt the $p-a-\mathrm{Si}: \mathrm{H} / \mathrm{i}-a-\mathrm{SiC}: \mathrm{H}$ interface. ${ }^{1}$ The recombination loss at the $p / i$ interface reduces, and hence, the UTA cell shows an increase in the collection efficiency in the short wavelength region as well as in $V_{\text {oc }}$. We suggest that the improvement of the dark conductivity of $p-a$ -SiC: $\mathrm{H}$ plays a dominant role by enhancing $V_{\text {oc }}$ and FF. We prepared thicker $(200 \mathrm{~nm} p-a-\mathrm{SiC}: \mathrm{H}$ single layers onto Corning 7059 glass substrates, and then assessed the dark conductivity values using $\mathrm{Al}$ and coplanar gap $(1 \mathrm{~mm})$-cell electrodes. The dark conductivity improves from 1.0 $\times 10^{-6} \mathrm{~S} / \mathrm{cm}$ to $3.0 \times 10^{-6} \mathrm{~S} / \mathrm{cm}$ by UTA process. Taking into account the $\mathrm{UV}$ penetration limit in $p-a-\mathrm{SiC}: \mathrm{H}$, the dark conductivity improvement may be more effective in the case of the thin $p-a-\mathrm{SiC}: \mathrm{H}$ windows layer. This can be ascribed to the ionization of $\mathrm{B}$ atoms induced by the excited $\mathrm{Ar}$ due to UV illumination as well as by migration of $\mathrm{H}$, which are inevitable in structural modification during the UTA process.

Figure 5 provides a band diagram of the fabricated $a$ $-\mathrm{Si}: \mathrm{H}$ based solar cell that explains the increase in the built-in potential $\left(\Delta V_{\mathrm{bi}}\right)$ by using the UTA. It is concluded that the increase in the dark conductivity of the $p-a-\mathrm{SiC}: \mathrm{H}$ window layer improves the built-in potential: (i) by lowering a barrier potential $\left(\Phi_{\mathrm{b} 2}-\Phi_{\mathrm{b} 1}\right)$ between the $\mathrm{SnO}_{2}: \mathrm{F}$ transpar- ent front electrode and the $p-a-\mathrm{SiC}: \mathrm{H}$ window layer and (ii) by the band lift arising from the Fermi Level location of $p$ $-a-\mathrm{SiC}: \mathrm{H}$ closer to the valence band edge $E_{v}$ of the $i-a$ $-\mathrm{Si}: \mathrm{H}$ absorber. ${ }^{3}$

The increase in $V_{\text {oc }}$ and FF via the UT process is not so high. It can be ascribe to the small increase in the dark conductivity of the $p-a-\mathrm{SiC}: \mathrm{H}$ window layer only via UV irradiation. In this case, the collection efficiency of the UT cell in the short wavelength region as high as the reference cell since the increase in the light absorption in the $p$ layer caused by the thickness enhancement compensates the reduction of recombination at the $p / i$ interface.

In summary, we attempted the UTA process upon the $p$ $-a-\mathrm{SiC}: \mathrm{H}$ window layer to improve the $p / i$ interface of the $a-\mathrm{Si}: \mathrm{H}$ based solar cell. This process improves $V_{\mathrm{oc}}$ and $\mathrm{FF}$ by an effective improvement of the built-in potential due to the dark conductivity enhancement of the $p-a-\mathrm{SiC}: \mathrm{H}$ window layer. The ultrathin contaminant $p-a-\mathrm{SiC}: \mathrm{H}$ formation during this process is also beneficial. This layer plays as a buffer layer increasing $J_{\mathrm{sc}}$ and $V_{\mathrm{oc}}$. Therefore, the conversion efficiency improves by $\sim 16 \%$. Since this process does not considerably impact the film thickness unlike the hydrogen post-treatment, ${ }^{5}$ it can be easily applied to the fabrication of $a$-Si:H based solar cells by the photo-CVD technique.

The authors gratefully acknowledge the Asahi Glass Company for providing them with Asahi $U$-type glass substrates. The Korea National R\&D Project for Nano Science and Technology supported this research.

${ }^{1}$ K. S. Lim, M. Konagai, and K. Takahashi, J. Appl. Phys. 56, 538 (1984). ${ }^{2}$ C. H. Lee, J. W. Jeon, and K. S. Lim, J. Appl. Phys. 87, 8778 (2000).

${ }^{3}$ S. Y. Myong, S. S. Kim, and K. S. Lim, J. Appl. Phys. 95, 1525 (2004).

${ }^{4}$ S. Okamoto, Y. Hishikawa, S. Tsuge, M. Sasaki, K. Ninomiya, M. Nishikuki, and S. Tawada, Jpn. J. Appl. Phys., Part 1 33, 1773 (1994).

${ }^{5}$ J. H. Jang and K. S. Lim, Appl. Phys. Lett. 71, 1846 (1997).

${ }^{6}$ M. Jana, D. Das, and A. K. Barua, J. Appl. Phys. 91, 5442 (2002).

${ }^{7}$ P. P. Ray, P. Chaudhuri, and P. Chatterjee, Thin Solid Films 403-404, 275 (2002).

${ }^{8}$ H. M. Branz, Y. Xu, S. Heck, and W. Gao, Appl. Phys. Lett. 81, 3353 (2002).

${ }^{9}$ G. E. Jellison and F. A. Modine, Appl. Phys. Lett. 69, 371 (1996); 69, 2137 (1996).

${ }^{10}$ J. Koh, A. S. Ferlauto, P. I. Rovira, C. R. Wronski, and R. W. Collins, Appl. Phys. Lett. 75, 2286 (1996).

${ }^{11}$ S. Y. Myong, S. S. Kim, and K. S. Lim, Thin Solid Films 455-456, 482 (2004).

${ }^{12}$ S. Y. Myong, H. K. Lee, E. Yoon, and K. S. Lim, J. Non-Cryst. Solids 298, 131 (2002).

${ }^{13}$ A. H. Mahan, D. L. Williamson, B. P. Nelson, and R. S. Crandall, Phys. Rev. B 40, 12024 (1989). 